\title{
Do You Transfer Your Skills? From Sports to Health Management in Cancer Patients
}

\author{
Valeria Sebri ${ }^{1,2 *}$, Lucrezia Savioni ${ }^{1,2}$, Stefano Triberti1,2, Ilaria Durosini ${ }^{2}$, Ketti Mazzocco ${ }^{1,2}$ \\ and Gabriella Pravettoni ${ }^{1,2}$ \\ ${ }^{1}$ Department of Oncology and Hemato-Oncology, University of Milan, Milan, Italy, ${ }^{2}$ Applied Research Division for Cognitive \\ and Psychological Science, IEO, European Institute of Oncology IRCCS, Milan, Italy
}

Skill transfer is a process where personal cognitive and behavioral abilities are applied to contexts that are different from the one in which they were originally learned. Literature demonstrates that skill transferability is possible: for example, people can apply skills learned in sports to other life-domains (such as school, work, or health management) with the aim to improve individual characteristics and reach personal goals. To do this, several factors, such as positive communication, adequate context, a person-centered perspective, and specific strategies, are necessary. On the basis of this, the aim of this contribution is explore the relationship between sports and health management skills to enhance the coach/athlete as well as the patient/physician relationships. Useful strategies for skill transfer from sports to cancer management are shown.

\footnotetext{
Keywords: skill transfer, sport, skills, health management, coach, physician, sport psychologist, subject-centered perspective
}

\section{INTRODUCTION}

Skills may be defined as individual characteristics that orient and affect human performances in everyday life activity that can also be trained to reach desirable, if not optimal, levels of functioning (e.g., goal setting, emotional management, and leadership) (Pierce et al., 2017). Several researchers have highlighted that personal skills can be transferred and applied to contexts that are different from the ones in which they were originally learned (Papacharisis et al., 2005; Gould and Carson, 2008; Camiré et al., 2014).

However, how this process of skill transferability can be possible is under discussion (Turnnidge et al., 2014; Allen et al., 2015). First of all, it is not an automatic process, and it is not an outcome or a unique phase either (Danish et al., 2004; Camiré et al., 2012; Martinek and Lee, 2012). In 2017, Pierce, Gould, and Camiré defined the transferability as an ongoing process whereby an individual continually interacts and interprets his/her environments to produce positive or negative skill transfer outcomes. This process can manifest itself in various ways related to the individual's skills, characteristics, and motivation (Danish et al., 2004). Skill transferability can be easily performed among contexts similar to each other (Leberman and McDonald, 2016) and can be measured, for example, using self-report items (e.g., Aryee and Heng, 1990), questionnaires, or interviews (e.g., Lordly, 2008). For example, people can transfer skills and knowledge from primary school to secondary school. In contrast, when contexts are not similar, people can find it difficult to apply the acquired skills, and they might require higher-order thinking skills, metacognition, and a certain level of cognitive maturity (Martinek and Lee, 2012; Leberman and McDonald, 2016; 
Jacobs and Wright, 2018). However, even if skill transferability to different contexts is not an instantaneous process, there are significant life-circumstances in which it is essential to use one's skills to deal with emotions and difficulties (for example, if a person receives a cancer diagnosis, he/she must use their skills to deal with anxiety or sadness) (Faul et al., 2010; Syrjala et al., 2014).

Some researchers have highlighted important steps that can facilitate skill transferability to different life-contexts and help improve certain abilities (Gould and Carson, 2008), such as working on an individuals' perception of stress management, improving self-efficacy, and developing a personal character (Hardcastle et al., 2015). There are several factors that can improve skill transferability (Allen et al., 2015; Sackett and Gano-Overway, 2017):

(a) value perception of transferable skills

(b) awareness of learned skills and transfer context

(c) confidence in transfer capacity

(d) external support for transfer from significant others

(e) perseverance in case of failure

In particular, people must be aware of the skills learned and, consequently, of the possibility of transferring them (Petitpas et al., 2005).

Regarding the concept of skill transfer from one context to another, sports have a well-known history of being an attractive avenue for helping athletes to develop several skills (Gould et al., 2007; Camiré et al., 2012) and for being a relevant vehicle for the transfer of skills to other life domains (Goudas et al., 2005; Allen et al., 2015; Sebri et al., 2019). From this perspective, Gould and Carson (2008) said that skills are "those internal personal assets, characteristics, and skills such as goal setting, emotional control, self-esteem, and hard work ethic that can be facilitated or developed during sports and are transferred for use in non-sports settings" (p. 60). Skill transfer is important for both individual and team sports (Issurin, 2013). Generally, positive transfer of motor, conceptual, and perceptual variables occurs when sports are similar (Gorman et al., 2011). For example, soccer and rugby, as well as other invasion sports, demand perceptual elements of tracking the ball in flight (Causer and Ford, 2014). Moreover, skill transfer is influenced by the expertise of athletes. Expert athletes have an advantage when it comes to learning and transferring their abilities thanks to daily and continuous training (Moore and Müller, 2014). Nonetheless, the athlete is the main factor that influences skill transfer due to the involvement of his/her internal assets (e.g., demographic data), external assets (e.g., coach and sports psychologist), and previous experience of sports (Pierce et al., 2017) in individual as well as team sports.

From a practical point of view, sports promote cognitive development (e.g., memory, attention, and decision-making), self-perception, and emotions (Mann et al., 2007; Pesce et al., 2009; Pesce et al., 2013). Moreover, athletes learn behaviors and values (Camiré and Trudel, 2010) that are integrated into their own sense of Self by becoming competent in internal, rather than external, behavioral regulation (Deci and Ryan, 2000; Hodge and Lonsdale, 2011). In other words, sports have been considered to be able to promote an overall sense of identity as well as self-esteem (Danish et al., 2004) in accordance with an education "through the physical" and not just "of the physical" (Goudas, 2010). This may be specifically relevant in the field of health management where patients deal with disease and its consequences, as these are also linked to their sense of Self and identity (Zebrack, 2000; Little et al., 2002). Applying skills previously learned to a health management context could be very useful to the pursuit of good treatment results.

\section{HOW CAN WE TRANSFER ABILITIES?}

Studies have distinguished between two processes to explain how skills can be transferred from one context to another: the implicit and explicit processes (Sackett and Gano-Overway, 2017). In the context of sport, the first process is related to the ability of athletes to transfer acquired skills without intention; the second one is related to a leadership figure, such as the sports coach, or a professional expert, such as the sport psychologist, who intentionally teach abilities and skills with the aim to transfer them in other life domains (Turnnidge et al., 2014; Pierce et al., 2018).

\section{Implicit and Explicit Processes}

The implicit process does not require external support and does not depend on someone's intention to transfer personal skills (Camiré et al., 2018). Some factors have been highlighted as affecting the implicit transfer of skills: the level of competition, coach-athlete relationship, and peer group interactions, if positive. Conversely, through the explicit process, the coach can intentionally and systematically teach and train abilities (Danish et al., 2004; Papacharisis et al., 2005; Forneris et al., 2012). In order to facilitate transferability, creative environments, guide-driven coaches, or sport psychologists are necessary to develop personal abilities. The first is essential as being conducive to learning thanks to the presence of supportive sport-based relationships (Weiss et al., 2013; Turnnidge et al., 2014); the second one helps individuals to be more aware and confident of the transfer. To achieve these aims, indirect and direct strategies can be implemented (Weiss et al., 2013; Allen et al., 2015). Indirect strategies involve the creation of positive environments (Sackett and Gano-Overway, 2017); direct strategies, instead, consist of skills intentionally implemented through improved cognitive functions and clear rules that allow the transfer (Gould and Carson, 2008; Camiré and Trudel, 2010; Trottier and Robitaille, 2014). As literature says, explicit strategies are more useful to the gain of full use and transfer of skills to other contexts, and this thanks especially to the role of the environment and a guide (Bean and Forneris, 2017; Sackett and Gano-Overway, 2017).

\section{The Role of the Environment}

The environment plays an important role in association with training. It is indeed known that training or education sessions do not bring results if they takes place in an environment that is not suitable for learning (Baker et al., 2003; Gould and Carson, 2008; Camiré et al., 2014). An optimal environment suitable for skill 
transfer is characterized by attitudes that facilitate participants' autonomy when making decisions and a feeling of competence when interacting with a sports environment (Sarrazin et al., 2002; Bartholomew et al., 2010; Bengoechea et al., 2017): a context in which effort, self-referenced improvement, and enjoyment are reinforced and where mistakes are seen as valuable instrument for learning (O'Rourke et al., 2013). Duda (2013) defined an "empowering" environment as one that is characterized by a taskinvolving motivational climate where significant others (such as coaches) are autonomy-supportive and socially supportive. A positive and empowering context is composed of the Five Cs - competence, confidence, connection, character, and caring (Lerner et al., 2005) - with the aim to make athletes free to express themselves. Thus, if a sport coach fosters a positive environment for the athletes and provides good leadership, the sportive setting will be more conducive to the development of life skills (Gould et al., 2007). Only in a context structured for athlete expertise and its specific characteristics can coach and athlete collaborate effectively (Doty, 2006; Voss et al., 2010; Lyras and Peachey, 2011), as these are essential prerequisites for transferring gained abilities from a sports context to a real-world context (Giorgi, 2005).

\section{Relevant Figures in Sports-to-Health Transferability}

People are not always aware of the abilities that are developed during training and, consequently, they do not always have the confidence to employ these skills in other life domains. In this regard, different figures can play an important role.

Generally, from childhood, parents are typically the most influential individuals in children's lives (Knight et al., 2016). Even in the context of sports, parents in the sampling years have a great and lasting effect on children's sport involvement (Wylleman et al., 2007). In adult life, the role of the romantic partner also seems to gain importance, influencing the perception of conflict, individual's eating, and conversation satisfaction (Dailey et al., 2011). The role of coaches can be useful for the ability of athletes to understand learned skills and employ them in other contexts (Petitpas et al., 2005; Camiré and Trudel, 2010; Trudel and Bernard, 2013; Marsollier et al., 2019). To this aim, coaches have to perceive and legitimize their role as being responsible for the positive development of an athlete, which often does not happen (Trottier and Robitaille, 2014; Galatti et al., 2016; Super et al., 2016; Bean and Forneris, 2017). Coaches can reinforce athletes' motivation and progress, making players active learners who are able to assess situations instead of just passive recipients of training (Denison, 2007; Cushion and Robyn, 2014). In recent years, some programs have been implemented with this objective. One of them is, for example, the Transfer-Ability Programme (TAP), created by Allen et al. (2015), which is a 1-week intervention based on sports conducted at a school. The aim of this sport-based intervention was to make participants aware of seven skills learned in the sporting contexts that are available in the academic environment. These sportbased interventions prove that skill transferability is possible, and coaches have identified five factors that can support this process: pride, opportunities, rewards, support from peers, and transfer experience. Thus, it is important that coaches continually learn and improve their abilities in developing players' skills in an athlete-centered approach for development (Vella et al., 2011; Trottier and Robitaille, 2014; Hardcastle et al., 2015).

In order to sustain athletes' holistic development, the sport psychologist is a relevant figure (Friesen and Orlick, 2010). Over the times, sport psychologists have become more and more important in several individual and group sports and may help athletes not only to improve their sport performance but also to improve their quality of living outside of sports (Friesen and Orlick, 2010). Different studies have shown the role of emotions and motivations during sports that can negatively influence athletes' performances (Di Corrado et al., 2013; Di Corrado, 2017). A sport psychologist can work with athletes to find the right motivations and to learn to manage emotions that could be harmful to the performance and learn to use those that are useful to obtain a peak performance (Martin et al., 2005; Chennaoui et al., 2016). The sport psychologist can also collaborate with coaches to take into consideration not just performances and goals but also athletes' quality of life (Friesen and Orlick, 2010). Pay attention to athletes' different personality and dispositional attributes have an influence of their body/mind state for performance (Harmison, 2011) (for example, knowing athletes' psychological profiles could help them to cope with stress, anxiety, and depression that can emerge during competitions) (Chennaoui et al., 2016).

Some of the available strategies introduced during training could be breathing techniques, imagery/visualization, positive self-talk, and goal setting where the role of a sport psychologist is to assist and support the development of the whole athlete as a person (Bond, 2002). This holistic consultation is important in association with the definition of the individual as a compilation of multiple selves, each with its own needs, roles, and stressors in a continuous and mutual interaction (Friesen and Orlick, 2010). Moreover, sport psychologists can assist coaches to promote their awareness development related to their own personal needs, such as job insecurity, time management, and performance anxiety. Exploring feelings, behaviors, and thoughts becomes the first step for building a working and trust alliance (Giges et al., 2004; Sharp and Hodge, 2013).

\section{SKILLS IN SPORT AS WELL AS IN ONCOLOGICAL HEALTH MANAGEMENT}

Up until now, we have explored the field of transferability related to essential skills for individual development and improvement in various contexts. Sport in particular is considered to be a special environment in which personal abilities can be learned and transferred. For example, Camiré et al. (2012) conducted a qualitative study and highlighted that coaches and athletes believed that athletes could transfer the skills gained through sports to other life domains.

Based on the themes outlined in this manuscript, our aim has been to deepen understand of the relationship between sports and health management to further explain skill transfer. 
An interesting field in which to consider the effects of sporthealth management transferability is that of cancer.

Tumor diagnosis is a shock experience for patients and their family, and it may elicit overwhelming feelings (Fallowfield, 2008; Fioretti et al., 2016; Triberti et al., 2019b). A cancer diagnosis can elicit experiences of uncertainty linked to existential challenges or changes in lifestyle as well as the everlasting fear of recurrence (Rottmann et al., 2010; Gnagnarella et al., 2016; Triberti et al., 2019a). During and after oncological treatments, physical and cognitive functions are involved. Moreover, cancer interventions, such as chemotherapy, radiotherapy, and hormonotherapy, can produce symptoms of "chemobrain," which causes cognitive dysfunction in addition to an overall discomfort in terms of mood disorders, convulsions, and vascular complications (Ganz, 2012; Patel et al., 2014). There are indeed consequences to treatment during each phase of disease (prevention, screening, diagnosis, treatment, survival, or end of life) as it makes daily life decisions more complicated in terms of the application of cognitive skills and flexibility (Pardon et al., 2013). However, the management and treatment of a disruptive disease is an occasion for the patient to be engaged in important bonds: within a patient-centered approach, the physician is usually a patient's safety guide during a condition of uncertainty (Rottmann et al., 2010), and this is similar to the role played by a coach in sports. The doctor is indeed not only an expert consultant but also a point of reference for people at a particularly vulnerable time. Different studies have shown that a good and personal patient-physician relationship is of vital importance to cancer patients (Vogel et al., 2006) for a better therapeutic outcome and shared decision making (Arora, 2003; Barth and Lannen, 2011; Kane et al., 2014; Renzi et al., 2016). The same is true for the coach-athlete relationship: the behaviors of coaches in the form of involvement, autonomy-supportive behaviors, and provision of structure have a beneficial impact on athletes' needs for autonomy, motivation, and competence (Mageau and Vallerand, 2003). Additionally, communication is a key function of obtaining a desirable relationship with others. In a doctor-patient relationship, both the patient and the doctor become part of a shared experience in which communication becomes the vehicle to exchanging implicit and explicit information, values, and emotions (Roter, 2000). As stated by Epstein et al. (2005), good and efficient patient-centered communication includes the (a) elicitation and understanding of the patient's perspective (i.e., ideas, concerns, expectations, needs, functioning, and feelings), (b) understanding the patient within his/her psychosocial context, (c) reaching a shared understanding of the disease and the treatment with the patient in line with the patient's values, and (d) helping patients to share responsibility and power by involving patients in choices. Specifically, it is important that physicians (i) assess what the patient already knows. They should check what a patient knows about his/her condition to see what is already understood or misunderstood. Patients must be able to express their perplexities and preferences (Ishikawa et al., 2013); (ii) assess what patients want/need to know. Patients need to know and understand what is happening and the available treatment options, but not all patients want detailed information (Baxi et al., 2013); (iii) are empathic. They should not ignore or minimize patients' feelings but should aim to understand and listen. Good communication has to be supportive and empathic to create a cooperative patient-physician relationship in a context perceived as safe (Hall et al., 2010; Kullberg et al., 2015); (iv) slow down and provide information in slow and deliberate fashion in order to give patients the time he/she needs to comprehend the new information. The physician has to use comprehensible language and be thorough as well as pay attention to patients' life habits, emotions, and fears in order to understand their needs (Pham et al., 2014); (v) keep it simple, using short statements and simple explanations (Morriss et al., 2010); (vi) tell the truth and not minimize the impact of what they are saying (Khalil, 2013); (vii) be hopeful, as the value of conveying hope in some situations should not be underestimated (Werner and Steihaug, 2017); (viii) watch the patient's body language and facial expressions, paying attention to non-verbal communication (Pawlikowska et al., 2012); and (ix) be prepared for patients' reactions, as each patient will react to a situation differently (Mazilu et al., 2010).

This way, the comprehension and management of cancer experiences are possible; physicians can use a variety of alternative strategies to facilitate the exchange of information with cancer patients and their families. These methods could also include audiovisual aids, teaching, the Internet, telephone helplines, and written materials. Good information exchange has been recognized as useful to increase patients' control and involvement in their care by reducing their psychological distress, encouraging better levels of adherence, and instilling realistic expectations (McPherson, 1993). Some sports strategies and skills are therefore useful also for health management, especially in an oncological context where doctor-patient communication foresees a co-construction and activation by both interlocutors. How could the transfer of skills previously learned in sport to oncological contexts be made sustainable?

\section{WHAT ARE THE AVAILABLE STRATEGIES FOR SKILL TRANSFER?}

In accordance with what has been mentioned above, sports could be an excellent field in which to promote skill transferability. Even if people with previous sports experience can show more easily transferable abilities, non-sport people could also profit from sports interventions and enact skill transfer in other contexts. So, how does the transfer process take place? There are some available "strategies" to promote skill transferability from sport to health management through the coach and sports psychologist involvement (see Table 1 below):

1. Focus on the need and willingness to transfer intentionally: individuals must be aware of the value of a specific skill while being willing to transfer it into another context; specifically, in working on comprehension, confidence, and support/reinforcement in transferability, the coach may organize appropriate training in which the value, trust, and strength of the transfer are supported (Camiré et al., 2012).

2. Improving and reinforcing skills beyond sport: coaches may promote the skill transfer, for example, with slogans, 
TABLE 1 | Strategies used by coaches to promote skill transfer from sports to health management.

\begin{tabular}{|c|c|c|}
\hline Strategies & Effect on skills & What the coach and the psychologist should do \\
\hline Willingness of transfer intentionally & $\begin{array}{l}\text { Comprehension, confidence, support, and reinforcement } \\
\text { in transfer }\end{array}$ & $\begin{array}{l}\text { Organize specific training to support the transfer of value } \\
\text { and trust }\end{array}$ \\
\hline Keywords, slogan, and examples & $\begin{array}{l}\text { Comprehension of the abilities that are transferred and } \\
\text { memorize related information }\end{array}$ & Explain experiences and provide examples \\
\hline A positive coach-athlete relationship & $\begin{array}{l}\text { Activating and reinforcing connections between the sport } \\
\text { and the "real-life" experience; creating a positive context } \\
\text { that supports human flourishing }\end{array}$ & $\begin{array}{l}\text { Meet athletes' family, give also positive feedbacks, take into } \\
\text { consideration individual differences and needs }\end{array}$ \\
\hline Debriefing and peer debriefing & Internalizing abilities learned in athletes' Sense of Self & Clarify learning outcomes and give meaning to actions \\
\hline Team imagery sessions & Imagine real-life contexts in which to apply skills & Plan these sessions and encourage players to imaging \\
\hline
\end{tabular}

keywords, and clear examples from their experience that players can comprehend, keep in mind, and easily apply in other life-domains (Gould and Carson, 2008; Trottier and Robitaille, 2014; Pierce et al., 2017);

3. Creating a positive coach-athlete relationship: putting genuine attention to the athletes' life beyond sport and emotions over performances (Gould and Carson, 2008; Camiré et al., 2011), by meeting, for example, athletes' family (Bowers et al., 2014) and providing feedbacks not only when a negative behavior is observed (Olushola et al., 2013; Hardcastle et al., 2015). It is important that the coach considers the athletes beyond their sporting role as individuals with different needs and characteristics;

4. Debriefing and peer debriefing to make athletes reflect on the process (Hellison, 2011): to help athletes to clarify learning outcomes, coaches have to make actions meaningful in order to facilitate the integration of skills learned through sport into their sense of Self (Berlin et al., 2007; Gilbert, 2011);

5. Having team imagery sessions before or after practices: the coaches have to encourage players to visualize reallife contexts in which they can apply the learned skills (Jacobs and Wright, 2018).

To sum up, previous sport experiences could be an important occasion to easily develop and improve skills that can be applied to health management contexts if needed. In other non-sport cases, the training and application of sport skills is suggested.

\section{DISCUSSION}

With the aim to explore how the transfer of skills is possible, we have shown various factors and available strategies. These elements are involved both in sport and health management contexts because they are essential for promoting abilities and reaching goals. Despite the fact that people who never played sports before could have difficulties in involving themselves in sport activities (Khan et al., 2012), most evidence highlights that playing sports can improve cardiovascular function, aerobic and metabolic fitness, reduce adiposity, and improve postural balance (Oja et al., 2015); in addition, sports can increase selfesteem and social support (Smith et al., 2012), also for people with physical and/or intellectual disabilities (Eime et al., 2013; Richardson et al., 2017). At the same time, possible factors of influence to be engaged in physical activities could be: (1) peer/group support: having other member involved in the same activities in term of strengths and emotional difficulties; (2) being part of a group: especially with the perception of the own group as being important and essential; (3) enjoy activities: being interest and glad to play sports; (4) having transports to reach the gym; and (5) having time to dedicate (Elmagd et al., 2018; Hutzler and Bergman, 2011).

The present work has aimed to focus not just on sports and its benefits, but also on its role as a vehicle of skill transferability. Skills could be recovered and adapted from previous sports experiences to enhance skills in cancer management contexts. Specifically, acquired competencies concerned non-verbal communication (e.g., bodily messages) and the comprehension and management of experiences to deal with in safety and collaborative contexts. In addition, some useful questionnaires may be adjusted to study patients' profile of mood state in oncological patients as well as in other pathological diseases for improving their quality of life (Di Corrado et al., 2013; Kim and Smith, 2017). There are some examples of methods developed in sport that have then been applied to health and vice versa. For instance, some perceptual-motor techniques are similarly used to optimize rhythmic movements in sports (e.g., Schaffert et al., 2011; Sors et al., 2015) and health contexts (e.g., Pau et al., 2016; Ghai et al., 2018; Murgia et al., 2018; Mezzarobba et al., 2018), for a review, see Schaffert et al. (2011, 2019). Another example is the Profile of Mood States (POMS, McNair et al., 1971; Di Corrado et al., 2014); initially developed in a clinical context, it is now widely used both in health (e.g., Di Corrado et al., 2013; Kim and Smith, 2017) and sports situations (e.g., Di Corrado et al., 2014; Chennaoui et al., 2016; Murgia et al., 2016; Di Corrado, 2017).

Moreover, within training as well as oncological treatments, a multidisciplinary collaboration of professionals is recommended. On one hand, the figure of sport psychologists may be suggested to increase awareness of skills and their application when involving both coaches and athletes (Pain and Harwood, 2004; Gee, 2010); on the other hand, the participation of coaches with specific sport programs during and after cancer treatments can modify parameters in patients' quality of life, fatigue, and depression by promoting skills (Baumann and Bloch, 2013; Bouillet et al., 2015). It is possible that skill transfer will be more useful in certain phases of illness management. For example, patients may be able to use individual resources and skills in condition of psychological and emotional balance than acute disease conditions. For example, people who are able to 
maintain emotional balance are better adjusted to use coping skills and specific strategies for handling complex situations (Batool, 2011). Moreover, we have to consider the relevance of health management beyond treatments (e.g., cancer survivors) when people have to deal with other changes after disease to rebuild their daily activities.

\section{CONCLUSION}

In conclusion, in light of the themes depicted in the present manuscript, we can hypothesize that oncological patients with previous experience of athlete-coach collaboration may be favored in the application of skills because these are learned and employed already. In other cases, the addition of sport/physical activities programs during and after oncological treatments to start working on skills is suggested. The introduction of sport competencies to transfer them to health management is harder but possible, even if people have had no previous sports experiences. This could be very useful in order to promote better treatments. Future studies may develop this hypothesis and its consequences in health domains.

\section{REFERENCES}

Allen, G., Rhind, D., and Koshy, V. (2015). Enablers and barriers for male students transferring life skills from the sports hall into the classroom. Qual. Res. Sport Exerc. Health 7, 53-67. doi: 10.1080/2159676X.2014.893898

Arora, N. K. (2003). Interacting with cancer patients: the significance of physicians' communication behavior. Soc. Sci. Med. 57, 791-806. doi: 10.1016/S02779536(02)00449-5

Aryee, S., and Heng, L. J. (1990). A note on the applicability of an organizational commitment model. Work Occup. 17, 229-239. doi: 10.1177/ 0730888490017002005

Baker, J., Côté, J., and Abernethy, B. (2003). Sport-specific practice and the development of expert decision-making in team ball sports. J. Appl. Sport Psychol. 15, 12-25. doi: 10.1080/10413200305400

Barth, J., and Lannen, P. (2011). Efficacy of communication skills training courses in oncology: a systematic review and meta-analysis. Ann. Oncol. 22, 1030-1040. doi: 10.1093/annonc/mdq441

Bartholomew, K. J., Ntoumanis, N., and Thøgersen-Ntoumani, C. (2010). The controlling interpersonal style in a coaching context: development and initial validation of a psychometric scale. J. Sport Exerc. Psychol. 32, 193-216. doi: 10.1123/jsep.32.2.193

Batool, S. S. (2011). Emotional intelligence based treatment in mental illness: a prospective analysis. Pak. J. Soc. Sci. 31, 251-259.

Baumann, F. T., and Bloch, W. (2013). Physical activity in oncology. Eur. Rev. Aging Phys. Act. 10:5. doi: 10.1007/s11556-012-0109-1

Baxi, S. S., Shuman, A. G., Corner, G. W., Shuk, E., Sherman, E. J., Elkin, E. B., et al. (2013). ). Sharing a diagnosis of HPV-related head and neck cancer: the emotions, the confusion, and what patients want to know. Head Neck 35, 1534-1541. doi: 10.1002/hed.23182

Bean, C., and Forneris, T. (2017). Is life skill development a by-product of sport participation? Perceptions of youth sport coaches. J. Appl. Sport Psychol. 29, 234-250. doi: 10.1080/10413200.2016.1231723

Bengoechea, E. G., Wilson, P. M., and Dunn, S. (2017). From liability to challenge: complex environments are associated with favorable psychosocial outcomes in adolescent sport participants. J. Adolesc. 58, 74-83. doi: 10.1016/j.adolescence. 2017.05.004

Berlin, R. A., Dworkin, A., Eames, N., Menconi, A., and Perkins, D. F. (2007). Examples of sports based youth development programs. New Dir. Youth Dev. 115, 85-106. doi: $10.1002 / y d .225$

\section{AUTHOR CONTRIBUTIONS}

VS conceptualized the ideas presented in the manuscript and wrote the first draft. LS contributed with conceptualization and writing. ST supervised the writing and edited the manuscript. ID contributed with substantial revisions to the final version of the manuscript. KM contributed with important intellectual content and final revision. GP contributed with important intellectual content and supervised the whole process.

\section{ACKNOWLEDGMENTS}

This work was partially supported by the Italian Ministry of Health with Ricerca Corrente and $5 \times 1000$ funds for IEO European Institute of Oncology IRCCS. ST and GP were supported by MIUR - Italian Ministry of University and Research (Departments of Excellence Italian Law n.232, 11th December 2016) for University of Milan. ID was supported by Fondazione Umberto Veronesi. VS and LS are Ph.D. students within the European School of Molecular Medicine (SEMM).

Bond, J. (2002). Applied sport psychology: philosophy, reflections, and experience. Int. J. Sport Psychol. 33, 19-37.

Bouillet, T., Bigard, X., Brami, C., Chouahnia, K., Copel, L., Dauchy, S., et al. (2015). Role of physical activity and sport in oncology: scientific commission of the national federation sport and cancer CAMI. Crit. Rev. Oncol. Hematol. 94, 74-86. doi: 10.1016/j.critrevonc.2014.12.012

Bowers, E. P., Johnson, S. K., Buckingham, M. H., Gasca, S., Warren, D. J., Lerner, J. V., et al. (2014). Important non-parental adults and positive youth development across mid- to late-adolescence: the moderating effect of parenting profiles. J. Youth Adolesc. 43, 897-918. doi: 10.1007/s10964-0140095- $\mathrm{x}$

Camiré, M., Forneris, T., Trudel, P., and Bernard, D. (2011). Strategies for helping coaches facilitate positive youth development through sport. J. Sport Psychol. Action 2, 92-99. doi: 10.1080/21520704.2011.584246

Camiré, M., Kendellen, K., Rathwell, S., and Felber Charbonneau, E. (2018). Evaluation of the pilot implementation of the coaching for life skills program. Int. Sport Coach. J. 5, 227-236. doi: 10.1123/iscj.2018-0006

Camiré, M., and Trudel, P. (2010). High school athletes' perspectives on character development through sport participation. Phys. Educ. Sport Pedagogy 15, 193207. doi: 10.1080/17408980902877617

Camiré, M., Trudel, P., and Forneris, T. (2012). Coaching and transferring life skills: philosophies and strategies used by model high school coaches. Sport Psychol. 26, 243-260. doi: 10.1123/tsp.26.2.243

Camiré, M., Trudel, P., and Forneris, T. (2014). Examining how model youth sport coaches learn to facilitate positive youth development. Phys. Educ. Sport Pedagogy 19, 1-17. doi: 10.1080/17408989.2012.726975

Causer, J., and Ford, P. R. (2014). "Decisions, decisions, decisions": transfer and specificity of decision-making skill between sports. Cogn. Process. 15, 385-389. doi: 10.1007/s10339-014-0598-0

Chennaoui, M., Bougard, C., Drogou, C., Langrume, C., Miller, C., Gomez-Merino, D., et al. (2016). Stress biomarkers, mood states, and sleep during a major competition: "Success" and "Failure" Athlete's profile of high-level swimmers. Front. Physiol. 7:94. doi: 10.3389/fphys.2016.00094

Cushion, C. J., and Robyn, L. J. (2014). A bourdieusian analysis of cultural reproduction: socialisation and the 'Hidden Curriculum' in professional football. Sport Educ. Soc. 19, 276-298. doi: 10.1080/13573322.2012.66 6966

Dailey, R. M., Romo, L. K., and Thompson, C. M. (2011). Confirmation in couples' communication about weight management: an analysis of how both partners 
contribute to individuals' health behaviors and conversational outcomes. Hum. Commun. Res. 37, 553-582. doi: 10.1111/j.1468-2958.2011.01414.x

Danish, S., Forneris, T., Hodge, K., and Heke, I. (2004). Enhancing youth development through sport. World Leis. J. 46, 38-49. doi: 10.1080/04419057. 2004.9674365

Deci, E. L., and Ryan, R. M. (2000). The "what" and "why" of goal pursuits: human needs and the self-determination of behavior. Psychol. Inq. 11, 227-268. doi: 10.1207/s15327965pli1104_01

Denison, J. (2007). Social theory for coaches: a foucauldian reading of one Athlete's poor performance. Int. J. Sports Sci. Coach. 2, 369-383. doi: 10.1260/ 174795407783359777

Di Corrado, D. (2017). Biological underpinnings of mood and the role of physical exercise. Sport Sci. Health 13, 461-468. doi: 10.1007/s11332-017-0374-5

Di Corrado, D., Agostini, T., Bonifazi, M., and Perciavalle, V. (2014). Changes in mood states and salivary cortisol levels following two months of training in elite female water polo players. Mol. Med. Rep. 9, 2441-2446. doi: 10.3892/mmr. 2014.2115

Di Corrado, D., Murgia, M., and Agostini, T. (2013). The patient on hemodialysis: psychological and management difficulties. Clin. Ter. 164, 21-24. doi: 10.7417/ CT.2013.1505

Doty, J. (2006). Sports build character?! J. Coll. Character 7:3. doi: 10.2202/19401639.1529

Duda, J. L. (2013). Introduction to the special issue on the PAPA project. Int. J. Sport Exerc. Psychol. 11, 307-310. doi: 10.1080/1612197x.2013.839415

Eime, R. M., Young, J. A., Harvey, J. T., Charity, M. J., and Payne, W. R. (2013). A systematic review of the psychological and social benefits of participation in sport for adults: informing development of a conceptual model of health through sport. Int. J. Behav. Nutr. Phys. Act. 10:135. doi: 10.1186/1479-586810- 135

Elmagd, A. M., Tiwari, U., Mossa, A. H., and Tiwari, D. (2018). Barriers of sports participation in higher education in the UAE. J. Phys. 2:40.

Epstein, R. M., Franks, P., Fiscella, K., Shields, C. G., Meldrum, S. C., Kravitz, R. L., et al. (2005). Measuring patient-centered communication in patient-physician consultations: theoretical and practical issues. Soc. Sci. Med. 61, 1516-1528. doi: 10.1016/j.socscimed.2005.02.001

Fallowfield, L. J. (2008). Treatment decision-making in breast cancer: the patientdoctor relationship. Breast Cancer Res. Treat. 112(Suppl. 1), 5-13. doi: 10.1007/ s10549-008-0077-3

Faul, L. A., Jim, H. S., Williams, C., Loftus, L., and Jacobsen, P. B. (2010). Relationship of stress management skill to psychological distress and quality of life in adults with cancer. Psycho Oncol. 19, 102-119. doi: 10.1002/pon.1547

Fioretti, C., Mazzocco, K., Riva, S., Oliveri, S., Masiero, M., and Pravettoni, G. (2016). Research studies on patients' illness experience using the narrative medicine approach: a systematic review. BMJ Open 6:e011220. doi: 10.1136/ bmjopen-2016-011220

Forneris, T., Camiré, M., and Trudel, P. (2012). The development of life skills and values in high school sport: is there a gap between stakeholder's expectations and perceived experiences? Int. J. Sport Exerc. Psychol. 10, 9-23. doi: 10.1080/ 1612197X.2012.645128

Friesen, A., and Orlick, T. (2010). A qualitative analysis of holistic sport psychology consultants' professional philosophies. Sport Psychol. 24, 227-244. doi: 10.1123/ tsp.24.2.227

Galatti, L. R., Scaglia, A. J., Bettega, O. B., and Paes, R. R. (2016). Coaches' perceptions of youth players' development in a professional soccer club in Brazil: paradoxes between the game and those who play. Sports Coach. Rev. 5, 174-185. doi: 10.1080/21640629.2016.1201359

Ganz, P. A. (2012). Doctor, will the treatment you are recommending cause chemobrain? J. Clin. Oncol. 30, 229-231. doi: 10.1200/JCO.2011.39.4288

Gee, C. J. (2010). How does sport psychology actually improve athletic performance? A framework to facilitate athletes' and coaches' understanding. Behav. Modif. 34, 386-402. doi: 10.1177/0145445510383525

Ghai, S., Ghai, I., Schmitz, G., and Effenberg, A. O. (2018). Effect of rhythmic auditory cueing on parkinsonian gait: a systematic review and meta-analysis. Sci. Rep. 8:506. doi: 10.1038/s41598-017-16232-5

Giges, B., Petitpas, A. J., and Vernacchia, R. A. (2004). Helping coaches met their own needs: challenges for the sport psychology consultant. Sport Psychol. 18, 430-444. doi: 10.1123/tsp.18.4.430
Gilbert, J. (2011). Teaching sport psychology to high school student-athletes: the psychological UNIFORM and the game plan format. J. Sport Psychol. Action 2, 1-9. doi: 10.1080/21520704.2010.549740

Giorgi, A. (2005). Remaining challenges for humanistic psychology. J. Hum. Psychol. 45, 204-216. doi: 10.1177/0022167804274361

Gnagnarella, P., Dragà, D., Baggi, F., Simoncini, M. C., Sabbatini, A., Mazzocco, K., et al. (2016). Promoting weight loss through diet and exercise in overweight or obese breast cancer survivors (InForma): study protocol for a randomized controlled trial. Trials 17:363. doi: 10.1186/s13063-016-1487-x

Gorman, A. D., Abernethy, B., and Farrow, D. (2011). Investigating the anticipatory nature of pattern perception in sport. Mem. Cogn. 39, 894-901. doi: 10.3758/ s13421-010-0067-7

Goudas, M. (2010). Prologue: a review of life skills teaching in sport and physical education. Hell. J. Psychol. 7, 241-258.

Gould, D., and Carson, S. (2008). Life skills development through sport: current status and future directions. Int. Rev. Sport Exerc. Psychol. 1, 58-78. doi: 10. 1080/17509840701834573

Gould, D., Collins, K., Lauer, L., and Chung, Y. (2007). Coaching life skills football: a study of award winning high school coaches. J. Appl. Sport Psychol. 19, 16-37. doi: 10.1080/10413200601113786

Goudas, V. P., Danish, S. J., and Theodorakis, Y. (2005). The effectiveness of teaching a life skills program in a 247-sport context. J. Appl. Sport 17:254.

Hall, J., Peat, M., Birks, Y., Golder, S., Entwistle, V., Gilbody, S., et al. (2010). Effectiveness of interventions designed to promote patient involvement to enhance safety: a systematic review. Qual. Saf. Health Care 19:e10. doi: 10.1136/ qshc. 2009.032748

Hardcastle, S. J., Tye, M., Glassey, R., and Hagger, M. S. (2015). Exploring the perceived effectiveness of a life skills development program for highperformance athletes. Psychol. Sport Exerc. 16, 139-149. doi: 10.1016/j. psychsport.2014.10.005

Harmison, R. J. (2011). Peak performance in sport: identifying ideal performance states and developing athletes' psychological skills. Prof. Psychol. Res. Pr. 37:233. doi: 10.1037/0735-7028.37.3.233

Hellison, D. (2011). Teaching Personal and Social Responsibility Through Physical Activity. Leeds: Human Kinetics.

Hodge, K., and Lonsdale, C. (2011). Prosocial and antisocial behavior in sport: the role of coaching style, autonomous vs. controlled motivation, and moral disengagement. J. Sport Exerc. Psychol. 33, 527-547. doi: 10.1123/jsep.33.4.527

Hutzler, Y., and Bergman, U. (2011). Facilitators and barriers to participation while pursuing an athletic career. Ther. Recreation J. 45, 1-16.

Ishikawa, H., Hashimoto, H., and Kiuchi, T. (2013). The evolving concept of "patient-centeredness" in patient-physician communication research. Soc. Sci. Med. 96, 147-153. doi: 10.1016/j.socscimed.2013.07.026

Issurin, V. B. (2013). Training transfer: scientific background and insights for practical application. Sports Med. 43, 675-694. doi: 10.1007/s40279-0130049-6

Jacobs, J. M., and Wright, P. M. (2018). Transfer of life skills in sport-based youth development programs: a conceptual framework bridging learning to application. Quest 70, 81-99. doi: 10.1080/00336297.2017.1348304

Kane, H. L., Halpern, M. T., Squiers, L. B., Treiman, K. A., and McCormack, L. A. (2014). Implementing and evaluating shared decision making in oncology practice. CA Cancer J. Clin. 64, 377-388. doi: 10.3322/caac. 21245

Khalil, R. B. (2013). Attitudes, beliefs and perceptions regarding truth disclosure of cancer-related information in the Middle East: a review. Palliat. Support. Care 11, 69-78. doi: 10.1017/S1478951512000107

Khan, K. M., Thompson, A. M., Blair, S. N., Sallis, J. F., Powell, K. E., Bull, F. C., et al. (2012). Sport and exercise as contributors to the health of nations. Lancet 380, 59-64. doi: 10.1016/S0140-6736(12)60865-4

Kim, J., and Smith, T. (2017). Exploring measurement invariance by gender in the profile of mood states depression subscale among cancer survivors. Qual. Life Res. 26, 171-175. doi: 10.1007/s11136-016-1452-x

Knight, C. J., Dorsch, T. E., Osai, K. V., Haderlie, K. L., and Sellars, P. A. (2016). Influences on parental involvement in youth sport. Sport Exerc. Perform. Psychol. 5:161. doi: 10.1037/spy0000053

Kullberg, A., Sharp, L., Johansson, H., and Bergenmar, M. (2015). Information exchange in oncological inpatient care - patient satisfaction, participation, and safety. Eur. J. Oncol. Nurs. 19, 142-147. doi: 10.1016/j.ejon.2014.10.005 
Leberman, S., and McDonald, L. (2016). The Transfer of Learning: Participants' Perspectives of Adult Education and Training. Burlington, VT: Gower.

Lerner, R. M., Lerner, J. V., Almerigi, J., Theokas, C., Phelps, E., Gestsdottir, S., et al. (2005). Positive youth development, participation in community youth development programs, and community contributions of fifth grade adolescents: findings from the first wave of the 4- $\mathrm{H}$ study of positive youth development. J. Early Adolesc. 25, 17-71. doi: 10.1177/027243160427 2461

Little, M., Paul, K., Jordens, C. F. C., and Sayers, E. J. (2002). Survivorship and discourses of identity. Psycho Oncol. 11, 170-178. doi: 10.1002/pon.549

Lordly, D. (2008). The challenge of skill transfer: dietitian perspectives. Can. J. Diet. Pract. Res. 69, 106-108. doi: 10.3148/69.2.2008.106

Lyras, A., and Peachey, W. J. (2011). Integrating sport-for-development theory and praxis. Sport Manag. Rev. 14, 311-326. doi: 10.1016/j.smr.2011.05.006

Mageau, G. A., and Vallerand, R. J. (2003). The coach-athlete relationship: a motivational model. J. Sports Sci. 21, 883-904. doi: 10.1080/ 0264041031000140374

Mann, D. T. Y., Williams, A. M., Ward, P., and Janelle, C. M. (2007). Perceptualcognitive expertise in sport: a meta-analysis. J. Sport Exerc. Psychol. 29, 457-478. doi: 10.1123 /jsep.29.4.457

Marsollier, É, Trottier, C., and Falcão, W. R. (2019). Development and transfer of life skills in figure skating: experiences of athletes and their coaches. Qual. Res. Sport Exerc. Health. doi: 10.1080/2159676x.2019.1659392

Martin, G. L., Vause, T., and Schwartzman, L. (2005). Experimental studies of psychological interven- tions with athletes in competitions: why so few? Behav. Modif. 29, 615-641.

Martinek, T., and Lee, O. (2012). From community gyms to classrooms. J. Phys. Educ. Recreat. Dance 83, 33-51. doi: 10.1080/07303084.2012.1059 8709

Mazilu, L., Niculescu, Z., Suceveanu, A. I, Suceveanu, A. P., Tofolean, D., and Adam, T. (2010). Ethical aspects of communication with cancer patients. Rev. Rom. Bioet. 8, 181-188.

McNair, D., Lorr, M., and Doppleman, L. (1971). POMS Manual for the Profile of Mood States. San Diego, CA: Educational and Industrial Testing Service.

McPherson, S. L. (1993). Knowledge representation and decision-making in sport. Adv. Psychol. 102, 159-188. doi: 10.1016/S0166-4115(08)61 470-3

Mezzarobba, S., Grassi, M., Pellegrini, L., Catalan, M., Kruger, B., Furlanis, G., et al. (2018). Action observation plus sonification. A novel therapeutic protocol for Parkinson's patient with freezing of gait. Front. Neurol. 8:723. doi: 10.3389/ fneur.2017.00723

Moore, C. G., and Müller, S. (2014). Transfer of expert visual anticipation to a similar domain. Q. J. Exp. Psychol. 67, 186-196. doi: 10.1080/17470218.2013. 798003

Morriss, R., Gask, L., Dowrick, C., Dunn, G., Peters, S., Ring, A., et al. (2010). Randomized trial of reattribution on psychosocial talk between doctors and patients with medically unexplained symptoms. Psychol. Med. 40, 325-333. doi: $10.1017 /$ S0033291709990353

Murgia, M., Forzini, F., Filho, E., Di Fronso, S., Sors, F., Bertollo, M., et al. (2016). How do mood states change in a multi-stage cycling competition? Comparing high and low performers. J. Sports Med. Phys. Fitness 56, 336-342.

Murgia, M., Pili, R., Corona, F., Sors, F., Agostini, T. A., Bernardis, P., et al. (2018). The use of footstep sounds as rhythmic auditory stimulation for gait rehabilitation in Parkinson's disease: a randomized controlled trial. Front. Neurol. 9:348. doi: 10.3389/fneur.2018.00348

Oja, P., Titze, S., Kokko, S., Kujala, U. M., Heinonen, A., Kelly, P., et al. (2015). Health benefits of different sport disciplines for adults: systematic review of observational and intervention studies with meta-analysis. Br. J. Sports Med. 49, 434-440. doi: 10.1136/bjsports-2014-093885

Olushola, J. O., Jones, D. F., Dixon, M. A., and Green, B. C. (2013). More than basketball: determining the sport components that lead to long-term benefits for African-American girls. Sport Manag. Rev. 16, 211-225. doi: 10.1016/j.smr. 2012.07.002

O’Rourke, D. J., Smith, R. E., Smoll, F. L., and Cumming, S. P. (2013). Parent-initiated motivational climate and young athletes' intrinsic-extrinsic motivation: cross-sectional and longitudinal relations. J. Child Adolesc. Behav. 1:109. doi: 10.4172/jcalb.1000109
Pain, M. A., and Harwood, C. G. (2004). Knowledge and perceptions of sport psychology within English soccer. J. Sports Sci. 22, 813-826. doi: 10.1080/ 02640410410001716670

Papacharisis, V., Goudas, M., Danish, S. J., and Theodorakis, Y. (2005). The effectiveness of teaching a life skills program in a sport context. J. Appl. Sport Psychol. 17, 247-254. doi: 10.1080/10413200591010139

Pardon, K., Chambaere, K., Roeline, W., Pasman, H., Deschepper, R., Rietjens, J., et al. (2013). Trends in end-of-life decision making in patients with and without cancer. J. Clin. Oncol. 31, 1450-1457. doi: 10.1200/JCO.2012.44. 5916

Patel, S. K., Hurria, A., and Mandelblatt, J. S. (2014). Chemobrain: is it time to initiate guidelines for assessment and management? Oncology 28, 809-810.

Pau, M., Corona, F., Pili, R., Casula, C., Sors, F., Agostini, T., et al. (2016). Effects of physical rehabilitation integrated with rhythmic auditory stimulation on spatiotemporal and kinematic parameters of gait in Parkinson's disease. Front. Neurol. 7:126. doi: $10.3389 /$ fneur.2016.00126

Pawlikowska, T., Zhang, W., Griffiths, F., van Dalen, J., and van der Vleuten, C. (2012). Verbal and non-verbal behavior of doctors and patients in primary care consultations-How this relates to patient enablement. Patient Educ. Couns. 86, 70-76. doi: 10.1016/j.pec.2011.04.019

Pesce, C., Crova, C., Cereatti, L., Casella, R., and Bellucci, M. (2009). Physical activity and mental performance in preadolescents: effects of acute exercise on free-recall memory. Ment. Health Phys. Act. 2, 16-22. doi: 10.1016/j.mhpa.2009. 02.001

Pesce, C., Crova, C., Marchetti, R., Struzzolino, I., Masci, I., Vannozzi, G., et al. (2013). Searching for cognitively optimal challenge point in physical activity for children with typical and atypical motor development. Ment. Health Phys. Act. 6, 172-180. doi: 10.1016/j.mhpa.2013.07.001

Petitpas, A. J., Cornelius, A. E., Van Raalte, J. L., and Jones, T. (2005). A framework for planning youth sport programs that foster psychosocial development. Sport Psychol. 19, 63-80. doi: 10.1123/tsp.19.1.63

Pham, A. K., Bauer, M. T., and Balan, S. (2014). Closing the patient-oncologist communication gap: a review of historic and current efforts. J. Cancer Educ. 29, 106-113. doi: 10.1007/s13187-013-0555-0

Pierce, S., Gould, D., and Camiré, M. (2017). Definition and model of life skills transfer. Int. Rev. Sport Exerc. Psychol. 10, 186-211. doi: 10.1080/1750984X. 2016.1199727

Pierce, S., Kendellen, K., Camiré, M., and Gould, D. (2018). Strategies for coaching for life skills transfer. J. Sport Psychol. Action 9, 11-20. doi: 10.1080/21520704. 2016.1263982

Renzi, C., Riva, S., Masiero, M., and Pravettoni, G. (2016). The choice dilemma in chronic hematological conditions: why choosing is not only a medical issue? A psycho-cognitive perspective. Crit. Rev. Oncol. Hematol. 99, 134-140. doi: 10.1016/j.critrevonc.2015.12.010

Richardson, E. V., Smith, B., and Papathomas, A. (2017). Disability and the gym: experiences, barriers and facilitators of gym use for individuals with physical disabilities. Disabil. Rehabil. 39, 1950-1957. doi: 10.1080/09638288. 2016.1213893

Roter, D. (2000). The enduring and evolving nature of the patient-physician relationship. Patient Educ. Couns. 39, 5-15. doi: 10.1016/s0738-3991(99) 00086-5

Rottmann, N., Helmes, A. W., and Vogel, B. A. (2010). Patients' needs and experiences at breast cancer diagnosis: how perceived threat influences the physician-patient interaction. J. Psycho. Oncol. 28, 157-172. doi: 10.1080/ 07347330903570529

Sackett, S. C., and Gano-Overway, L. A. (2017). Coaching life skills development: best practices and high school tennis coach exemplar. Int. Sport Coach. J. 4, 206-219. doi: 10.1123/iscj.2016-0080

Sarrazin, P., Vallerand, R., Guillet, E., Pelletier, L., and Cury, F. (2002). Motivation and dropout in female handballers: a 21-month prospective study. Eur. J. Soc. Psychol. 32, 395-418. doi: 10.1002/ejsp.98

Schaffert, N., Janzen, T. B., Mattes, K., and Thaut, M. H. (2019). A review on the relationship between sound and movement in sports and rehabilitation. Front. Psychol. 10:244. doi: 10.3389/fpsyg.2019.00244

Schaffert, N., Mattes, K., and Effenberg, A. O. (2011). An investigation of online acoustic information for elite rowers in on-water training conditions. J. Hum. Sport Exerc. 6, 392-405. doi: 10.4100/jhse.2011.62.20 
Sebri, V., Savioni, L., Triberti, S., Mazzocco, K., and Pravettoni, G. (2019). How to train your health: sports as a resource to improve cognitive abilities in cancer patients. Front. Psychol. 10:2096. doi: 10.3389/fpsyg.2019. 02096

Sharp, L. A., and Hodge, K. (2013). Effective sport psychology consulting relationships: two coach case studies. Sport Psychol. 27, 313-324. doi: 10.1123/ tsp.27.4.313

Smith, S. E., Grieve, F. G., Zapalac, R. K., Derryberry, W. P., and Pope, J. (2012). How does sport team identification compare to identification with other social institutions? J. Contemp. Athletics 6:69.

Sors, F., Murgia, M., Santoro, I., and Agostini, T. (2015). Audio-based interventions in sport. Open Psychol. J. 8, 212-219. doi: 10.2174/1874350101508010212

Super, S., Verkooijen, K., and Koelen, M. (2016). The role of community sports coaches in creating optimal social conditions for life skill development and transferability-a salutogenic perspective. Sport Educ. Soc. 23, 173-185. doi: 10.1080/13573322.2016.1145109

Syrjala, K. L., Jensen, M. P., Elena Mendoza, M., Yi, J. C., Fisher, H. M., and Keefe, F. J. (2014). Psychological and behavioral approaches to cancer pain management. J. Clin. Oncol. 32, 1703-1711. doi: 10.1200/JCO.2013.54.4825

Triberti, S., Gorini, A., Savioni, L., Sebri, V., and Pravettoni, G. (2019a). Avatars and the disease: digital customization as a resource for self-perception assessment in breast cancer patients. Cyberpsychol. Behav. Soc. Netw. 22, 558-564. doi: 10.1089/cyber.2018.0461

Triberti, S., Savioni, L., Sebri, V., and Pravettoni, G. (2019b). eHealth for improving quality of life in breast cancer patients: a systematic review. Cancer Treat. Rev. 74, 1-14. doi: 10.1016/j.ctrv.2019.01.003

Trottier, C., and Robitaille, S. (2014). Fostering life skills development in high school and community sport: a comparative analysis of the coach's role. Sport Psychol. 28, 10-21. doi: 10.1123/tsp.2012-0094

Trudel, P., and Bernard, D. (2013). A Case study of a high school sport program designed to teach athletes life skills and values. Sport Psychol. 27, 188-200. doi: $10.1123 /$ tsp.27.2.188

Turnnidge, J., Côté, J., and Hancock, D. J. (2014). Positive youth development from sport to life: explicit or implicit transfer? Quest 66, 203-217. doi: 10.1080/ 00336297.2013.867275
Vella, S., Oades, L., and Crowe, T. (2011). The role of the coach in facilitating positive youth development: moving from theory to practice. J. Appl. Sport Psychol. 23, 33-48. doi: 10.1080/10413200.2010.511423

Vogel, B. A., Helmes, A. W., and Bengel, J. (2006). Arzt-patienten-kommunikation in der tumorbehandlung: erwartungen und erfahrungen aus patientensicht. Zeitsch. Med. Psychol. 15, 149-161.

Voss, M. W., Kramer, A. F., Basak, C., Prakash, R. S., and Roberts, B. (2010). Are expert athletes 'expert' in the cognitive laboratory? A meta-analytic review of cognition and sport expertise. Appl. Cogn. Psychol. 24, 812-826. doi: 10.1002/ acp. 1588

Weiss, M. R., Stuntz, C. P., Bhalla, J. A., Bolter, N. D., and Price, M. S. (2013). “More than a game": impact of The First Tee life skills programme on positive youth development: project introduction and Year 1 findings. Qual. Res. Sport Exerc. Health 5, 214-244. doi: 10.1080/2159676X.2012.712997

Werner, A., and Steihaug, S. (2017). Conveying hope in consultations with patients with life-threatening diseases: the balance between supporting and challenging the patient. Scand. J. Prim. Health Care 35, 143-152. doi: 10.1080/02813432. 2017.1333322

Wylleman, P., Knop, P. D., Verdet, M. C., and Ceciě-Erpiě, S. (2007). "Social psychology in sport," in Parenting and Career Transitions of Elite Athletes, eds S. Jowett and D. Lavallee (Champaign, IL: Human Kinetics Publishers), 233-247

Zebrack, B. J. (2000). Cancer survivor identity and quality of life. Cancer Pract. 8, 238-242. doi: 10.1046/j.1523-5394.2000.85004

Conflict of Interest: The authors declare that the research was conducted in the absence of any commercial or financial relationships that could be construed as a potential conflict of interest.

Copyright (c) 2020 Sebri, Savioni, Triberti, Durosini, Mazzocco and Pravettoni. This is an open-access article distributed under the terms of the Creative Commons Attribution License (CC BY). The use, distribution or reproduction in other forums is permitted, provided the original author(s) and the copyright owner(s) are credited and that the original publication in this journal is cited, in accordance with accepted academic practice. No use, distribution or reproduction is permitted which does not comply with these terms. 